\title{
Scatter Analysis of Fatigue Life and Pore Size Data of Die-Cast AM60B Magnesium Alloy
}

\author{
S. Mohd, Y. Mutoh, Y. Otsuka, Y. Miyashita, T. Koike, and T. Suzuki
}

\begin{abstract}
Scatter behavior of fatigue life in die-cast AM60B alloy was investigated. For comparison, those in rolled AM60B alloy and die-cast A365-T5 aluminum alloy were also studied. Scatter behavior of pore size was also investigated to discuss dominant factors for fatigue life scatter in die-cast materials. Three-parameter Weibull function was suitable to explain the scatter behavior of both fatigue life and pore size. The scatter of fatigue life in die-cast AM60B alloy was almost comparable to that in die-cast A365-T5 alloy, while it was significantly large compared to that in the rolled AM60B alloy. Scatter behavior of pore size observed at fracture nucleation site on the fracture surface was comparable to that observed on the specimen cross-section and also to that of fatigue life. Therefore, the dominant factor for large scatter of fatigue life in die-cast alloys would be the large scatter of pore size. This speculation was confirmed by the fracture mechanics fatigue life prediction, where the pore observed at fatigue crack nucleation site was assumed as the pre-existing crack.
\end{abstract}

Keywords-Fatigue life, Pore size, Scatter, Weibull distribution, Die-cast magnesium alloy

\section{INTRODUCTION}

$\mathrm{T}$ HE utilization of die-cast magnesium alloy in automotive industries especially in powertrain components offers a prospect for light weighting to result in reduction in fuel consumption. Unfortunately, the die-cast products inhered a variety of casting defects such as porosity, oxide films and intermetallic particles, which are harmful to the mechanical properties, in particular, the fatigue behavior. It has been reported that fatigue-crack nucleation in cast AM60B is mainly caused by porosity [1],[2].

It is also known that scatter of size as well as type of defect affect the fatigue life of castings [3]-[5]. Scatter is an inherent

S. Mohd is with the Department of Materials Science, Nagaoka University of Technology, 1603-1 Kamitomioka, Nagaoka 940-2188, Japan, on leave from the Department of Aeronautical Engineering, Universiti Tun Hussein Onn Malaysia, 86400 Batu Pahat, Johor, Malaysia (phone: +8-125-847-9735; fax: +8-125-847-9770; e-mail: sofian@uthm.edu.my).

Y. Mutoh is with the Department of System Safety, Nagaoka University of Technology Kamitomioka 1603-1, Nagaoka, Niigata 940-2188, Japan (e-mail: mutoh@mech.nagaokaut.ac.jp).

Y. Otsuka is with the Department of System Safety, Nagaoka University of Technology Kamitomioka 1603-1, Nagaoka, Niigata 940-2188, Japan (e-mail: otsuka@vos.nagaokaut.ac.jp).

Y. Miyashita is with the Department of System Safety, Nagaoka University of Technology Kamitomioka 1603-1, Nagaoka, Niigata 940-2188, Japan (email: miyayuki@mech.nagaokaut.ac.jp).

T. Koike is with the Yamaha Motor Co. Ltd., Technology Center, Iwata, Shizuoka, 438-8501 Japan (e-mail: koiketoshikatsu@yamaha-motor.co.jp).

T. Suzuki is with the Yamaha Motor Co. Ltd., Technology Center, Iwata, Shizuoka, 438-8501 Japan (e-mail: suzukitakaharu@yamaha-motor.co.jp). characteristic of mechanical properties including fatigue behavior [6]. This characteristic is related to the reliability of the structures and the safety factor of the design. El Kadiri et al. [7] investigated the fatigue behavior of a high-pressure diecast magnesium AM50 alloy. The authors reported that the scatter of fatigue life was greater in the high-cycle fatigue regime than in the low-cycle fatigue regime. The scatter behavior was attributed by diversity, nature and size of defects. These defects have a particular influence on the incubation life in the high-cycle fatigue regime. Large shrinkage pore clusters were found to be the primary nucleation site for fatigue cracks. Horstemeyer et al. [8] reported that casting defects and microstructures influenced the distribution of fatigue life and crack propagation behavior of die-cast AZ91 Magnesium alloy in high cycle regime.

There are many research publications regarding to the evaluation of scatter in fatigue life by using Weibull distribution. Wang et al. [4] investigated the fatigue-life distribution of A356-T6 specimens. They reported that the scatter in fatigue life due to variation in nucleation pore size could be described by a two-parameter Weibull distribution function. The Weibull modulus which presenting degree of scatter was in the range of 1.6 to 2.0. For the cast Al-7Si- Mg alloy, where cracks were nucleated at oxide films, Nyahumwa et al. [9] found that the scatter in fatigue life was about 1.7 to 3.5 (for a two-parameter Weibull distribution). Yi et al. [10] investigated the scatter in fatigue life due to effect of porosity in cast A356-T6 Al-Si alloy, where the Weibull modulus was about 1.4 to 2.4 scatter in fatigue life (for a three-parameter Weibull distribution). However, there have been still less reports on statistical characteristics of fatigue life in magnesium alloys.

In the present study, scatter behavior of fatigue life in diecast AM60B magnesium alloy has been investigated in detail. The cause of fatigue life scatter has been discussed and correlated with fatigue life distribution estimated by fracture mechanics approach. For comparison, scatter behavior of fatigue life in die-cast A365-T5 aluminum alloy has been also investigated.

TABLE I

TENSILE PROPERTIES OF DIE-CAST AM60B MAGNESIUM ALLOY AND DIE-CAST A365-T5 ALUMINUM ALLOY

\begin{tabular}{ccccc}
\hline Material & $\begin{array}{c}0.2 \% \text { Proof strength, } \\
\mathrm{MPa}\end{array}$ & $\begin{array}{c}\text { Tensile strength, } \\
\mathrm{MPa}\end{array}$ & $\begin{array}{c}\text { Elongation, } \\
\%\end{array}$ & $\begin{array}{c}\text { Young's modulus, } \\
\mathrm{GPa}\end{array}$ \\
\hline AM60B & 122 & 221 & 7.0 & 43 \\
\hline A365-T5 & 211 & 316 & 5.0 & 75 \\
\hline
\end{tabular}




\section{EXPERIMENTAL PROCEDURE}

In the present work, the materials used were die-cast AM60B magnesium alloy $(6.1 \% \mathrm{Al}, 0.38 \% \mathrm{Mn}, 0.03 \% \mathrm{Zn}$, $0.02 \% \mathrm{Si}, 0.003 \% \mathrm{Fe}, 0.001 \% \mathrm{Cu}$ and balance $\mathrm{Mg}$ ) and diecast A365-T5 aluminum alloy $(11.5 \% \mathrm{Si}, 0.8 \% \mathrm{Mn}, 0.5 \%$ $\mathrm{Mg}, \quad 0.15 \% \mathrm{Fe}, 0.15 \% \mathrm{Ti}, 0.07 \% \mathrm{Zn}, 0.03 \% \mathrm{Cu}, 0.02 \% \mathrm{Sr}$, $0.001 \% \mathrm{P}$ and balance $\mathrm{Al}$ ). The tensile properties of both the materials are given in Tables I.

Four groups of plate samples were prepared and labeled as groups AM60B-1, AM60B-2, AM60B-3 and A365-T5, where AM60B-1 and AM60B-2 were different lots of die-casted magnesium alloy, AM60B-3 was a rolled magnesium alloy without casting defects, and A365-T5 was a die-casted aluminum alloy with $\mathrm{T} 5$ heat treatment. These plate samples were cut into $35 \times 10 \times 2 \mathrm{~mm}$ plate specimens. The surface of specimen was polished by using emery papers with grit numbers ranged from 600 to 1500 .

Four-point bending fatigue tests with inner and outer span lengths of $10 \mathrm{~mm}$ and $30 \mathrm{~mm}$ were carried out on a servohydraulic fatigue testing machine with $1 \mathrm{kN}$ load capacity. Sinusoidal wave form with a frequency of $20 \mathrm{~Hz}$ and stress ratio of 0.1 was used for the fatigue tests under controlled temperature of $20^{\circ} \mathrm{C}$ and relative humidity of $55 \% \mathrm{RH}$. The fatigue life scatter study was performed using 20 specimens at each stress level selected based on the S-N curves obtained. The fracture surfaces were observed and analyzed using a scanning electron microscope (SEM) and an energy dispersive spectroscopy (EDS). Statistic software was used to analyze the fatigue life scatter data and defect size data of the specimens.

\section{RESULTS AND DISCUSSION}

\section{A. S-N Curve}

Fig. 1 shows relationships between stress amplitude and number of cycles to failure for AM60B-1, AM60B-2, AM60B-3 and A365-T5 specimens. As seen from the figure, the rolled AM60B specimen has higher fatigue limit compared to those of die-cast AM60B specimens. Absence of casting defect in the rolled specimen would contribute to the higher fatigue limit. It is found from the figure that A365 aluminum alloy has the highest fatigue limit of $100 \mathrm{MPa}$, which would correspond to its higher tensile strength compared to AM60B magnesium alloy as shown in Table 1.

\section{B. Scatter Analysis}

\section{Scatter of Fatigue Life}

For fatigue life scatter study, the stress amplitude corresponding to fatigue life of $1 \times 10^{5}$ cycles has been chosen for each group of specimen, i.e. $77.5 \mathrm{MPa}$ (AM60B-1), $82.5 \mathrm{MPa}$ (AM60B-2), 100MPa (AM60B-3) and $110 \mathrm{MPa}$ (A365-T5). Fatigue tests of 20 specimens have been carried out at each stress amplitude and the results are shown in Fig. 2. As can be seen from Fig. 2, scatter in fatigue life was about 1 order of magnitude for the groups AM60B-2 and A365-T5. The scatter in fatigue life of the group AM60B-1 was double as compared to that of the group AM60B-2. This may

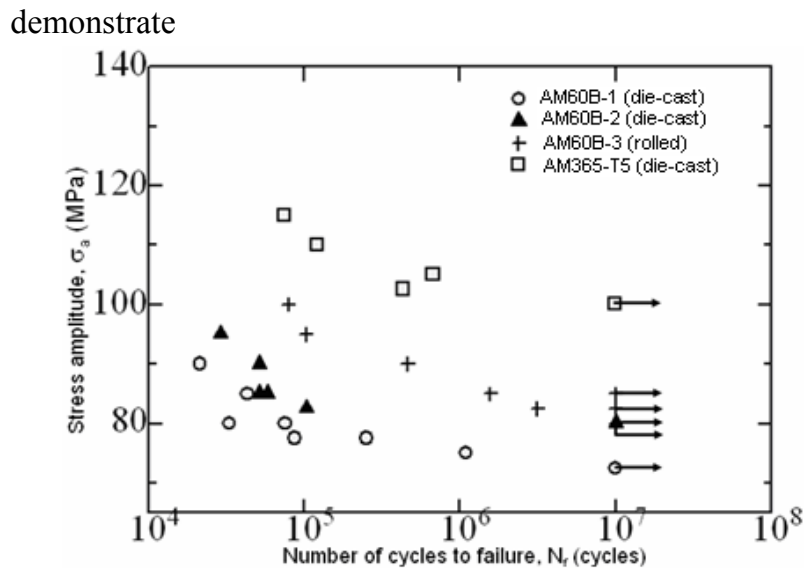

Fig. 1 Relationship between stress amplitude and number of cycles to failure for AM60B magnesium alloy and A365 aluminum alloy

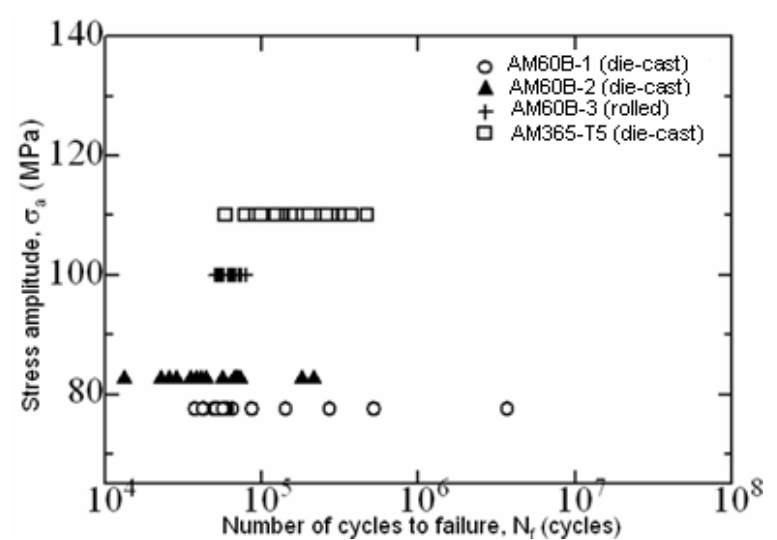

Fig. 2 Scatter of fatigue life for AM60B magnesium alloy and A365 aluminum alloy

one of fatigue life scatter characteristics of die-cast AM60B that the fatigue life scatter would become wider with a decrease in stress amplitude. For the rolled specimen group AM60B-3, the scatter of life was relatively small.

Fatigue life consists of two phases i.e. crack nucleation and crack propagation. The fatigue mechanism during the crack nucleation period is a surface phenomenon, while the latter phase is a material bulk phenomenon associated with the fatigue crack growth resistance of the material [11]. Surface roughness and casting defects serve as high stress concentration point for crack nucleation. The uniform surface roughness of AM60B-3 rolled specimens might contribute to the least fatigue life scatter. Variability in defect type and scatter of size would be the possible main factors contributing to the wide scatter of fatigue life in die-cast specimens.

\section{Statistical Analysis of Fatigue Life}

The Weibull distribution function was developed based on weakest link theory [12]. Due to its flexibility, the Weibull distribution has been widely used to describe fatigue life scatter data. In this study, the Weibull distribution function was adopted to describe the fatigue life scatter data and the analysis was performed using statistic software. There are two types of Weibull distribution function i.e. two parameter (2P) 
Weibull function and three parameter (3P) Weibull function. The cumulative distribution function (CDF) of both distribution functions are defined by the following equations:

$$
\begin{aligned}
& F\left(N_{f}\right)=1-\exp \left(-\left(\frac{N_{f}}{N_{a}}\right)^{m}\right) \\
& F\left(N_{f}\right)=1-\exp \left(-\left(\frac{N_{f}-N_{o}}{N_{a}-N_{o}}\right)^{m}\right)
\end{aligned}
$$

where $N_{f}$ is measured fatigue life; $F\left(N_{f}\right)$ is cumulative failure probability at $N_{f}, N_{o}$ and $N_{a}$ are nonzero threshold fatigue life and characteristic fatigue life, respectively; and $m$ is Weibull modulus which represents the variability of the data. The selection of the best distribution function that could sufficiently describe the fatigue life data was made based on the goodness of fit test.

The simple method to measure the goodness of fit is by using the coefficient of determination, $R^{2} . R^{2}$ explains how well the regression line represents the data. Perfect fitting, $R^{2}$ $=1$, occurs when all the data points lie exactly on a straight line. In practice, a selected probability distribution and its associated parameters will be accepted if $R^{2}>0.95$ [13] and some authors suggested that 0.90 as the minimum value of $R^{2}$. Table 2 shows the summary of $R^{2}$ and Weibull parameter for all groups of specimens.

The 3P Weibull function gives better fitting for all groups with $R^{2}>0.90$. This indicates that the fatigue life data of all four specimen groups could be sufficiently described by using 3P Weibull distribution function.

It was also found that the $\mathrm{m}$ value of the rolled specimen was the highest, which indicated the least scatter of fatigue life. The defect free specimens produced by rolling process resulted in an improvement in fatigue life scatter which is about 3 times than those of cast AM60B. The larger scatter of fatigue life in die-cast AM60B may be attributed by the wide scatter of pore size near surface in the die-cast material.

From the comparison of scatter in fatigue life between diecast magnesium alloy and die-cast aluminum alloy, no significant difference of scatter in fatigue life was found. J.Z. Yi et al. [5] \& [10] reported that the Weibull modulus, $m$, for cast A356-T6 with life (in cycles) between $10^{5}$ and $10^{6}$ is about 1.4 to 2.4. This suggests that die-cast magnesium alloy and die-cast aluminum alloy show similar fatigue life scatter behavior.

\section{Statistical Analysis of Fractographic Pore Size Data}

Failure behavior of the scatter study specimens was examined by using SEM and EDS machines. The result showed that porosity was the most harmful defect to fatigue life of cast products, where at least $75 \%$ of the total number of specimens for each group failed from porosity. In case of rolled AM60B-3 specimens, all of the specimens failed at specimen surface without influence of defect like pores.

The fracture surface observations are shown in Fig. 3. Crack nucleation point was identified from fracture surface, as shown in the figure. The fracture surface image obtained by SEM was

TABLE II

\begin{tabular}{|c|c|c|c|c|c|c|c|}
\hline \multirow{3}{*}{$\begin{array}{l}\text { Specimen } \\
\text { group }\end{array}$} & \multicolumn{3}{|c|}{ 2P Weibull distribution } & \multicolumn{4}{|c|}{ 3P Weibull distribution } \\
\hline & \multirow{2}{*}{$\mathrm{R}^{2}$} & \multicolumn{2}{|c|}{$\begin{array}{l}\text { Weibull } \\
\text { parameter }\end{array}$} & \multirow{2}{*}{$\mathbf{R}^{2}$} & \multicolumn{3}{|c|}{ Weibull parameter } \\
\hline & & $\mathrm{m}$ & $\mathrm{N}_{\mathrm{a}}$ & & $\mathrm{m}$ & $\mathrm{N}_{\mathrm{a}}$ & $N_{o}$ \\
\hline $\begin{array}{l}\text { AM60B-1 } \\
\text { (die-cast) }\end{array}$ & 0.8254 & 3.81 & 63030 & 0.9642 & 1.31 & 59219 & 34465 \\
\hline $\begin{array}{l}\text { AM60B-2 } \\
\text { (die-cast) }\end{array}$ & 0.9185 & 1.79 & 61054 & 0.9431 & 1.33 & 60066 & 7806 \\
\hline $\begin{array}{c}\text { AM60B-3 } \\
\text { (rolled) }\end{array}$ & 0.9722 & 9.93 & 65081 & 0.9840 & 3.84 & 64631 & 36845 \\
\hline $\begin{array}{c}\text { A365-T5 } \\
\text { (die-cast) }\end{array}$ & 0.9692 & 2.05 & 210749 & 0.9846 & 1.47 & 204435 & 36877 \\
\hline
\end{tabular}

SUMMARY OF WeIBULl PARAMETER AND R² FOR FATIGUE LIFE DATA

then analyzed by using image processing software to measure the pore size. Fig. 4 shows the examples of the pore images at crack nucleation point. AM60B specimens had the shrinkage pores at the crack nucleation points as shown in Fig. 4(a).Gas pores with regular shape (Fig. 4(b)) were found in some of A365 specimens. The closed curve in the figure indicated the boundary of the pore area, A. A pore size, $\mathrm{a}_{\mathrm{i}}$ was then estimated to be equal to $\sqrt{A}$.

In order to evaluate the effect of pore size distribution on scatter of fatigue life, the 3P Weibull distribution was employed to describe scatter of pore size. The summary of statistical results is shown in Table 3. The values of $R^{2}$ obtained indicated that $3 \mathrm{P}$ Weibull function can be used to describe scatter of defect size for three materials. As can be seen from Table 3, the defect size scatter characterized by $m$ value is almost corresponding to the scatter of fatigue life (Table 2) for both the die-cast AM60B and A365-T5. This confirms that the scatter of fatigue life is dominantly caused by the scatter of defect size.

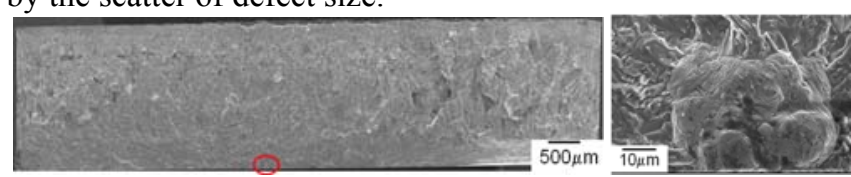

(a) Oxide inclusion $\left(\sigma_{\mathrm{a}}=77.5 \mathrm{MPa}, \mathrm{N}_{\mathrm{f}}=60840\right.$ cycles $)$

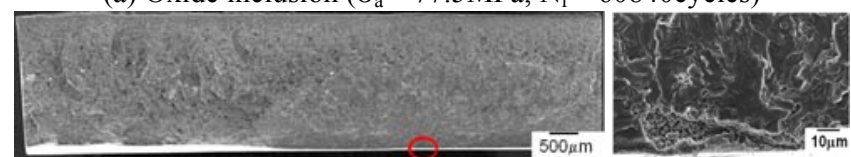

b) Shrinkage porosity $\left(\sigma_{\mathrm{a}}=82.5 \mathrm{MPa}, \mathrm{N}_{\mathrm{f}}=215576\right.$ cycles $)$

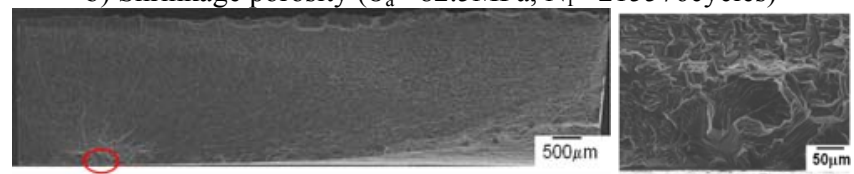

c) Crack initiated due to surface roughness $\left(\sigma_{\mathrm{a}}=100 \mathrm{MPa}, \mathrm{N}_{\mathrm{f}}=55288\right.$ cycles)

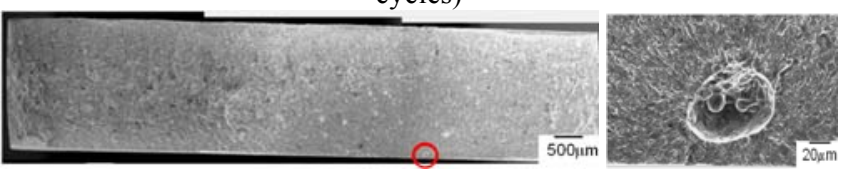

d) Gas porosity $\left(\sigma_{\mathrm{a}}=110 \mathrm{MPa}, \mathrm{N}_{\mathrm{f}}=338460\right.$ cycles $)$

Fig. 3 Fracture surface images for (a) AM60B-1, (b) AM60B-2, (c) AM60B-3, and (d) A365-T5 


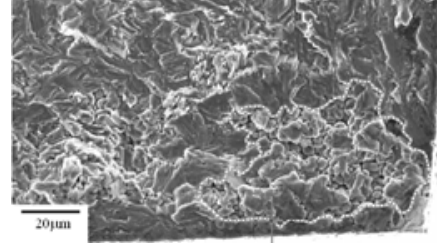

(a) AM60B-1

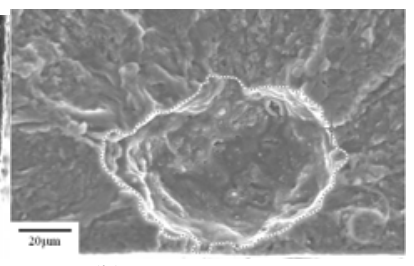

(b) A365-T5
Fig. 4 Pores at crack nucleation points for the AM60B-1 and A365T5 specimens

TABLE III

SUMMARY OF WEIBULL PARAMETER AND R ${ }^{2}$ FOR FRACTOGRAPHIC AND METALLOGRAPHIC PORE SIZE DATA

\begin{tabular}{|c|c|c|c|c|c|c|c|c|}
\hline \multicolumn{9}{|c|}{ METALLOGRAPHIC PORE SIZE DATA } \\
\hline \multirow{4}{*}{$\begin{array}{l}\text { Specimen } \\
\text { group }\end{array}$} & \multirow{2}{*}{\multicolumn{4}{|c|}{$\begin{array}{l}\text { Fractographic } \\
\text { Weibull distribution }\end{array}$}} & \multicolumn{4}{|c|}{ Metallographic } \\
\hline & & & & & \multicolumn{4}{|c|}{ 3P Weibull distribution } \\
\hline & \multirow{2}{*}{$\mathrm{R}^{2}$} & \multicolumn{3}{|c|}{ Weibull parameter } & \multirow{2}{*}{$\mathbf{R}^{2}$} & \multicolumn{3}{|c|}{ Weibull parameter } \\
\hline & & m & $a_{a}$ & $a_{0}$ & & m & $a_{a}$ & $a_{0}$ \\
\hline AM60B-1 & 0.9793 & 1.95 & 53.99 & 14.98 & 0.9805 & 1.17 & 54.87 & 23.10 \\
\hline AM60B-2 & 0.9633 & 1.96 & 52.79 & 14.99 & 0.9872 & 1.39 & 57.79 & 20.21 \\
\hline A365-T5 & 0.9742 & 1.41 & 108.88 & 46.47 & 0.9785 & 1.55 & 74.82 & 46.70 \\
\hline
\end{tabular}

\section{Fracture Mechanics Life Prediction}

To confirm the correlation between scatter of fatigue life and scatter of pore size discussed in the previous section, fracture mechanical prediction of fatigue life based on the pore size at fatigue crack nucleation site has been carried out. In the prediction, the pore was assumed as an initial crack and the predicted crack propagation life was presumed as the fatigue life. The fatigue crack propagation life was estimated by using the following equation:

$N_{f}=\frac{1}{C Y^{b} \Delta \sigma^{b} \pi^{b / 2}} \int_{a_{i}}^{a_{f}} a^{-b / 2} d a$

where, the values of material constants are $C=3 \times 10^{-10}, b=4$ for AM60B [14], $C=2.11 \times 10^{-11}, b=4$ for A365 (from fatigue crack growth plot), $a_{f}=1.5 \mathrm{~mm}$ (assuming that the final crack length is three-fourth of the specimen width), $\Delta \sigma$ is the stress amplitude, $a_{i}$ is the initial pore size and $Y$ is the geometry correction factor, and are equal to 0.7 [15] and 0.5 [16] for a surface and internal pore, respectively.

Fig. 5 illustrates relationship between experimental and predicted fatigue life. The plots in which the data points were distributed in the range of the factor-of-two indicated a good prediction of fatigue life. This satisfactory prediction within a scatter band of factor-of-two suggests that the fatigue life is strongly correlated with pore size. However, the experimental fatigue life of A365-T5 specimens was rather long compared to the predicted one. This may result from that the predicted fatigue life is corresponded to the crack propagation life and does not include the crack nucleation life.

\section{Statistical Analysis of Metallographic Pore Size Data}

The correlation between fatigue life distribution and metallographic pore size data was investigated. Four cross- sections with the size of $13 \times 2 \mathrm{~mm}$ were randomly cut from the specimen and observed by using an SEM. The cross-sectional

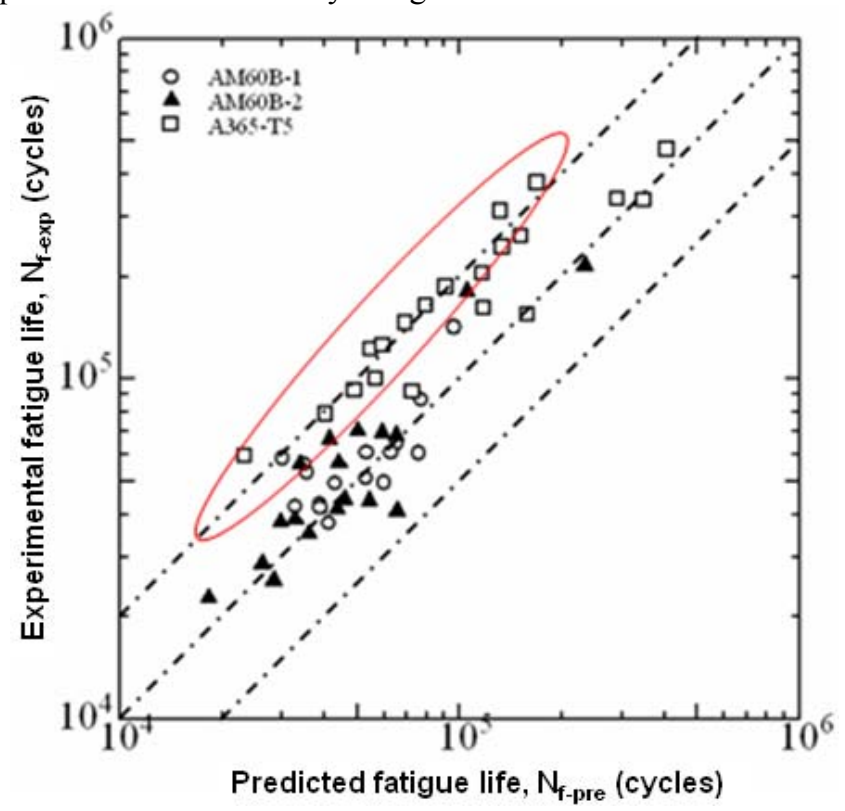

Fig. 5 Relationship between experimental fatigue life and predicted fatigue life

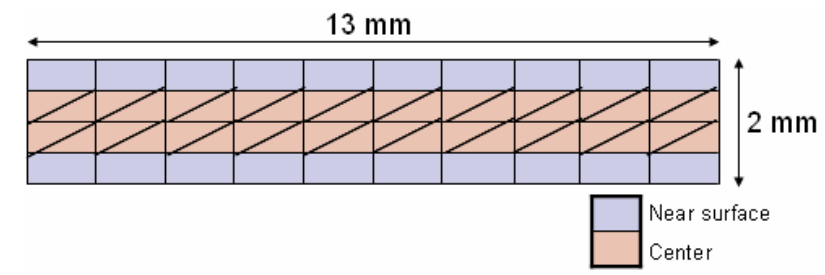

Fig. 6 Cross-sectional area for metallographic pore size measurement

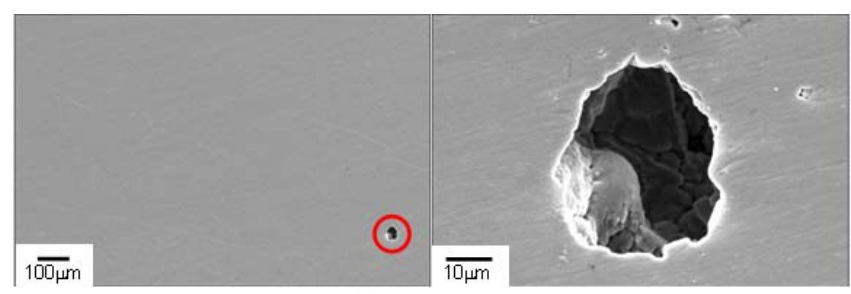

(a) AM60B-2

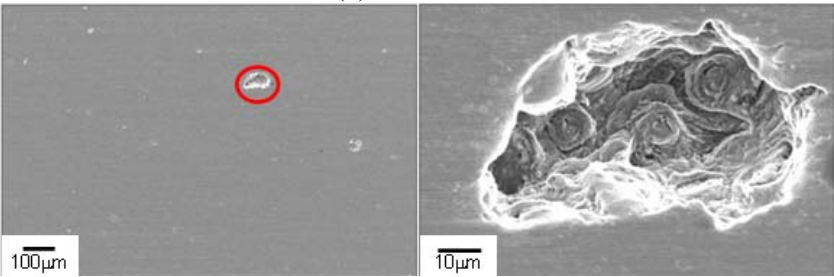

(b) A365-T5

Fig. 7 Gas pores observed on metallographic surface for AM60B-2 and A365-T5.

was sectioned into a unit of $1.3 \times 0.5 \mathrm{~mm}$ as shown in Fig. 6 . The largest pore in each unit was measured and recorded as a potential crack nucleation point. Fig. 7 shows the pore images observed in AM60B-2 (Fig. 7(a)) and A365-T5 (Fig. 7(b)) specimens. 
Initially, pore sizes near the surface layer and in the center layer were analyzed separately to examine the effect of cooling rate on pore size distribution. Cooling rate at the surface would be higher than that at the center of specimen. Pore size distribution plots for AM60B-1 and A365-T5 are shown in Fig. 8. The pore size distribution plots showed that the pore size distributions of near surface layer and center layer for both materials were comparable, which indicates that the cooling rate throughout the $2 \mathrm{~mm}$ thickness would be almost uniform. Therefore, both data were combined as a single pore size distribution for statistical analysis.

Fig. 8 also shows that the range of pore size which was observed on fatigue crack nucleation site is located in larger pore size compared to that observed on the cross-section. Similar results have been reported by Yi et al. [10] and Ting et al. [17].

Statistical analysis was performed for pore size data on the cross-section. In order to compare the scatter of pore size on the cross-section with that at crack nucleation site, the threshold pore size $\mathrm{a}_{\mathrm{th}}$ was calculated and considered as the minimum pore size that would initiate the crack at selected stress amplitude. The threshold stress intensity range $\Delta \mathrm{K}_{\mathrm{th}}$ used were 1.0 MPa $\sqrt{\mathrm{m}}$ [14] and 2.2 $\mathrm{MPa} \sqrt{\mathrm{m}}$ (from fatigue crack growth plot) for AM60B and A365-T5, respectively. The results showed the $a_{\text {th }}$ of $31.4 \mu \mathrm{m}$ (AM60B-1), $27.7 \mu \mathrm{m}$ (AM60B-2) and $75.3 \mu \mathrm{m}$ (A365-T5). These values were close to the minimum pore size measured on fracture surface of AM60B specimens i.e. $24.9 \mu \mathrm{m}$ (AM60B-1) and $28.9 \mu \mathrm{m}$ (AM60B-2). For A365-T5 specimen, the $a_{t h}$ obtained was larger than the minimum pore size measured on fracture surface which was $54.7 \mu \mathrm{m}$.

The results of statistic analysis are shown in Table 3. As indicated by the values of $\mathrm{R}^{2}, 3 \mathrm{P}$ Weibull distribution could be successfully applied to the metallographic pore size data. The $\mathrm{m}$ values obtained are close to those for pore size observed on the fracture surface.

The similarity in scatter behavior of fractographic and metallographic pore size data suggests that the fatigue life scatter of die-cast AM60B and A365-T5 at $10^{5}$ cycles can be predicted by using the scatter characteristics of metallographic pore size. Sufficient number of sampling pores will be required to make sure the collected data truly representing the actual pore size distribution.

\section{CONCLUSION}

1. A 3-Parameter Weibull distribution could be applicable to the fatigue life data as well as the pore size for the AM60B and A365-T5 alloys.

2. Scatter behavior of fatigue life for die-cast AM60B magnesium alloy was comparable to that for die-cast A365-T5 aluminum alloy.

3. Scatter in fatigue life of rolled magnesium alloy was significantly small compared to that of die-cast one: Weibull modulus for rolled one was about 3 times larger than that for die-cast one.

4. Fatigue lives of die-cast AM60B and A365-T5 alloys could be successfully predicted in the fracture mechanics approach, where the pore at crack initiation site was assumed as the preexisting crack.

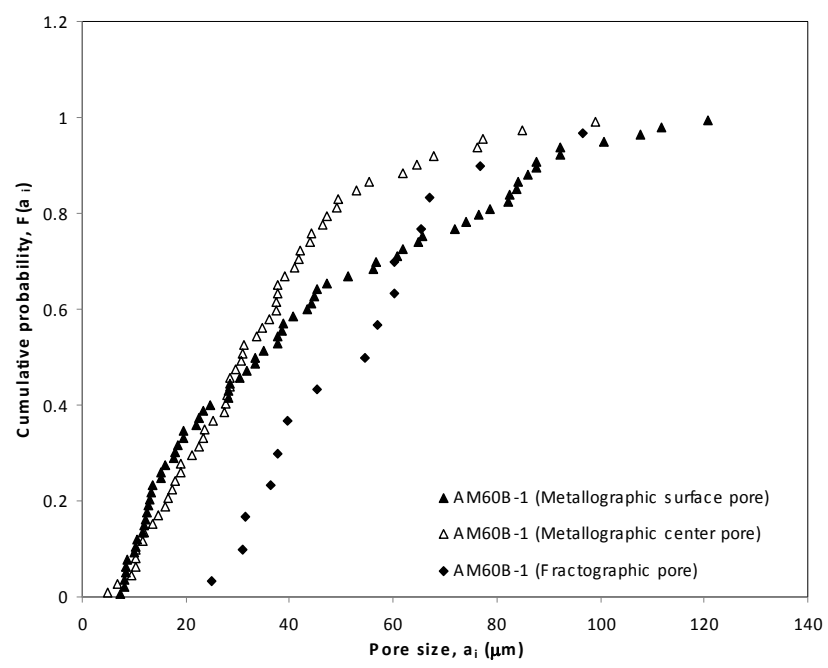

(a) AM60B-1

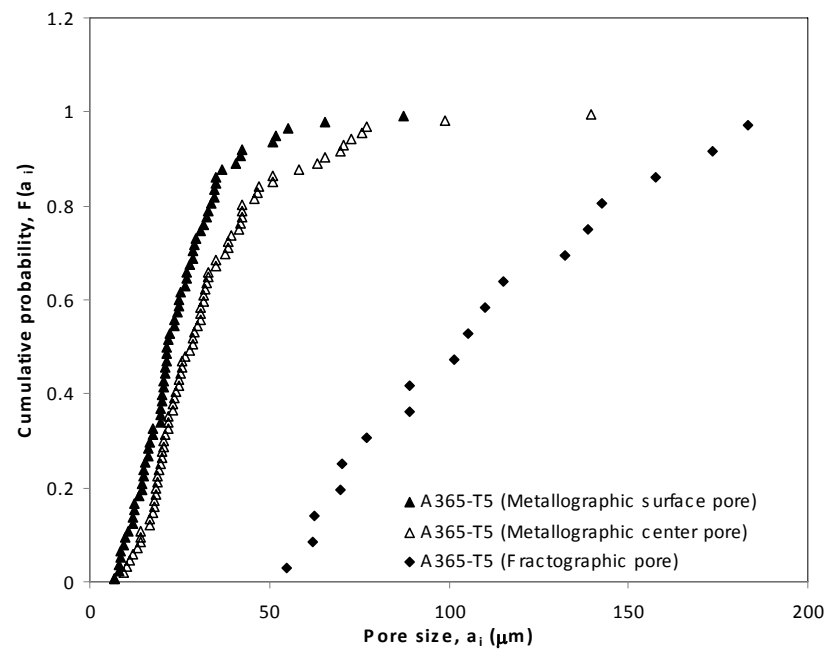

(b) A365-T5

Fig. 8 Comparison of pore size distribution between near surface layer and center layer for AM60B-1 and A365-T5

5. Scatter characteristics of pore size observed on the crosssection was almost comparable to that observed on the fracture nucleation site.

6. The scatter behavior of fatigue life for the die-cast materials was almost comparable to that of pore size. Therefore, scatter of pore size would be the main factor for the scatter in fatigue life of die-cast AM60B magnesium alloy and die-cast A365T5 aluminum alloy.

\section{REFERENCES}

[1] Y. Lu, F. Taheri, M.A. Gharghouri, and H.P. Han, "Experimental and numerical study of the effects of porosity on fatigue crack initiation of HPDC magnesium AM60B alloy," J. Alloys Compd., vol. 470, pp. 202213, 2008 .

[2] M.F. Horstemeyer, N. Yang, K. Gall, D. McDowell, J. Fan, and P. Gullet, "High cycle fatigue mechanisms in a cast AM60B magnesium 
alloy," Fatigue Fract. Engng. Mater Struct., vol. 25, pp. 1045-1056, 2002.

[3] B. Skallerud, T. Iveland, and G. Harkegard, "Fatigue life assessment of aluminum alloys with casting defects," Eng. Fract. Mech., vol. 44, pp. 857-874, 1993.

[4] Q.G. Wang, D. Apelian, and D.A. Lados, "Fatigue behavior of A356-T6 aluminum cast alloys. Part I. Effect of casting defects," J. Light Met., vol. 1, pp. 73-84, 2001.

[5] J.Z. Yi, P.D. Lee, T.C. Lindley, and T. Fukui, "Statistical modeling of microstructure and defect population effects on the fatigue performance of cast A356-T6 automotive components,” Mater. Sci. Eng. A, vol. 432, pp. 59-68, 2006.

[6] J. Schijve, Fatigue of Structures and Materials, Springer, 2008, pp. 373393.

[7] H. El Kadiri, Y. Xue, M.F. Horstemeyer, J.B Jordan, and P.T. Wang, "Identification and modeling of fatigue crack growth mechanisms in a die-cast AM50 magnesium alloy," Acta Metall., vol. 54, pp. 5061-5076, 2006.

[8] M.F. Horstemeyer, N. Yang, K. Gall, D. L. McDowell, J. Fan and P. M. Gullett, "High cycle fatigue of a die cast AZ91E-T4 magnesium alloy," Acta Materialia, 2004, vol. 52, pp.1327-1336.

[9] C. Nyahumwa, N.R. Green, and J. Campbell, "Influence of casting technique and hot isostatic pressing on the fatigue of an $\mathrm{Al}-7 \mathrm{Si}-\mathrm{Mg}$ alloy," Metall. Mater. Trans. A, vol. 32A, pp. 349-358, 2001.

[10] J.Z. Yi, Y.X. Gao, P.D. Lee, H.M. Flower, and T.C. Lindley, "Scatter in fatigue life due to effects of porosity in cast A356-T6 aluminum-silicon alloys," Metall. Mater. Trans. A, vol. 34, pp. 1879-1890, 2003.

[11] J. Schijve, "Statistical distribution functions and fatigue of structures," Inter. J. of Fatigue, vol. 27, pp. 1031-1039, 2005.

[12] W. Weibull, "A Statistical distribution function of wide applicability," J. Appl. Mech, 1951, vol. 18, pp. 293-297.

[13] X. Teng, H. Mae, Y. Bai, and T. Wierzbicki, Eng. Fract. Mech, 2009, "Pore size and fracture ductility of aluminum low pressure die casting," vol. 76, pp. 983-996, 2009

[14] S.A. Khan, "Effect of anodized layer on fatigue behavior under humid environment," Ph.D. Thesis, 2007, pp. 5.1-5.17.

[15] J.C. Newman, JR., and I.S. Raju, "An empirical stress-intensity factor equation for the surface crack," Engineering Fracture Mechanics, Pergamon Press Ltd.,1981, vol. 15, No. 1-2, pp. 185-192.

[16] Y. Murakami, "Metal Fatigue: Effect of Small Defects and Nonmetallic Inclusions," Elsevier Science Ltd, Boston, MA, 2002, pp. 369.

[17] J.C. Ting, V. Frederick, and F.V. Lawrence, JR, "Modeling the long-life fatigue behavior of a cast aluminum alloy," Fatigue Fract. Eng. Mater Struct., vol. 16, pp. 631-647, 1993. 